\title{
RESEARCH
}

Open Access

\section{Ecto-GPR37: a potential biomarker for Parkinson's disease}

Xavier Morató 1,2,3, Paula Garcia-Esparcia ${ }^{2,4,5}$, Josep Argerich ${ }^{1,2}$, Franc Llorens ${ }^{2,4,5,6}$, Inga Zerr ${ }^{6,7}$, Wojciech Paslawski ${ }^{3}$, Eva Borràs ${ }^{8,9}$, Eduard Sabidó ${ }^{8,9}$, Ulla E. Petäjä-Repo ${ }^{10}$, Víctor Fernández-Dueñas ${ }^{1,2}$, Isidro Ferrer ${ }^{2,4,5}$,

Per Svenningsson ${ }^{3}$ and Francisco Ciruela $a^{1,2^{*}}$ (i)

\begin{abstract}
Objective: a-Synuclein has been studied as a potential biomarker for Parkinson's disease (PD) with no concluding results. Accordingly, there is an urgent need to find out reliable specific biomarkers for PD. GPR37 is an orphan G protein-coupled receptor that toxically accumulates in autosomal recessive juvenile parkinsonism. Here, we investigated whether GPR37 is upregulated in sporadic PD, and thus a suitable potential biomarker for PD.
\end{abstract}

Methods: GPR37 protein density and mRNA expression in postmortem substantia nigra (SN) from PD patients were analysed by immunoblot and RT-qPCR, respectively. The presence of peptides from the N-terminus-cleaved domain of GPR37 (i.e. ecto-GPR37) in human cerebrospinal fluid (CSF) was determined by liquid chromatography-mass spectrometric analysis. An engineered in-house nanoluciferase-based immunoassay was used to quantify ectoGPR37 in CSF samples from neurological control (NC) subjects, PD patients and Alzheimer's disease (AD) patients.

Results: GPR37 protein density and mRNA expression were significantly augmented in sporadic PD. Increased amounts of ecto-GPR37 peptides in the CSF samples from PD patients were identified by mass spectrometry and quantified by the in-house ELISA method. However, the CSF total a-synuclein level in PD patients did not differ from that in NC subjects. Similarly, the cortical GPR37 mRNA expression and CSF ecto-GPR37 levels in AD patients were also unaltered.

Conclusion: GPR37 expression is increased in SN of sporadic PD patients. The ecto-GPR37 peptides are significantly increased in the CSF of PD patients, but not in AD patients. These results open perspectives and encourage further clinical studies to confirm the validity and utility of ecto-GPR37 as a potential PD biomarker.

Keywords: GPR37, Pael-R, Parkinson's disease, Cerebrospinal fluid, Biomarker, Alzheimer's disease, a-Synuclein, Orphan receptor

\footnotetext{
* Correspondence: fciruela@ub.edu

${ }^{1}$ Pharmacology Unit, Department of Pathology and Experimental Therapeutics, Faculty of Medicine and Health Sciences, Institute of Neurosciences, University of Barcelona, L'Hospitalet de Llobregat, Spain ${ }^{2}$ Neuroscience Program, Bellvitge Biomedical Research Institute, IDIBELL, L'Hospitalet de Llobregat, Spain

Full list of author information is available at the end of the article
}

C The Author(s). 2021 Open Access This article is licensed under a Creative Commons Attribution 4.0 International License, which permits use, sharing, adaptation, distribution and reproduction in any medium or format, as long as you give appropriate credit to the original author(s) and the source, provide a link to the Creative Commons licence, and indicate if changes were made. The images or other third party material in this article are included in the article's Creative Commons licence, unless indicated otherwise in a credit line to the material. If material is not included in the article's Creative Commons licence and your intended use is not permitted by statutory regulation or exceeds the permitted use, you will need to obtain permission directly from the copyright holder. To view a copy of this licence, visit http://creativecommons.org/licenses/by/4.0/ The Creative Commons Public Domain Dedication waiver (http://creativecommons.org/publicdomain/zero/1.0/) applies to the data made available in this article, unless otherwise stated in a credit line to the data. 


\section{Background}

Parkinson's disease (PD) is the second most common type of neurodegenerative disorder [1], with hallmarks of Lewy body (LB) formation and neuronal death and synaptic loss in the substantia nigra (SN) [2]. Cerebrospinal fluid (CSF) is an accessible source of brain-derived proteins and metabolites, which mirrors molecular changes that occur in the central nervous system. The decreased CSF levels of amyloid- $\beta 42$ (A $\beta 42)$ and altered content of tau protein species are used in clinical practice to aid diagnosis of Alzheimer's disease (AD) [3]. In contrast, although potential diagnostic/prognostic CSF biomarkers of PD (i.e. $\alpha$-synuclein species, lysosomal enzymes, markers of $A \beta$ and tau pathology, and neurofilament light chain) have been largely assessed, no conclusive data have been obtained. However, the combined assessment of some of these biomarkers in PD patients can provide more accurate diagnostic and prognostic results, which necessitate systematic studies confirming the validity and utility of combinations of certain CSF (and blood) PD/AD biomarkers for clinical practice [4, 5].

GPR37 is an orphan $G$ protein-coupled receptor (GPCR) expressed in brain regions such as cerebellum, corpus callosum, caudate nucleus, putamen, hippocampus and SN [6, 7]. The physiological function of this receptor has yet to be elucidated. A recent study has shown that GPR37 mediates the control of oligodendrocyte differentiation [8], but there is little information on the role of GPR37 in other glial cells and neurons. GPR37 is also known as a parkin-associated endothelinreceptor-like receptor (Pael receptor) [9] as it was originally identified as a substrate of parkin, an E3 ubiquitin ligase encoded by the PARK2 gene involved in ubiquitination and proteasome-mediated degradation/clearance of misfolded proteins [9-11]. Mutations in the PARK2 gene that lead to the loss of the ubiquitin ligase activity of parkin are the most common cause of autosomal recessive juvenile parkinsonism [10]. Consistently, an insoluble form of GPR37 has been reported to accumulate in the brains of AR-JP patients [9], suggesting a neuropathological role of this receptor in PD. In line with this, mice lacking GPR37 are partially protected against dopaminergic cell death caused by 1-methyl-4-phenyl-1,2,3,6tetrahydropyridine [12]. Nevertheless, in heterologous expression systems, GPR37 matures and is exported from the endoplasmic reticulum to the cell surface, where its long extracellular $\mathrm{N}$-terminus is rapidly and constitutively cleaved by metalloproteinases (MPs) [13]. Thus, the GPR37 ectodomain (i.e. ecto-GPR37) is released from cells by shedding, a phenomenon rarely described for GPCRs. Importantly, MPs have received much attention since they can cleave a large number of protein substrates (i.e. $\alpha$-synuclein, amyloid precursor protein, and Apolipoprotein E receptor), thus playing a potential role in neurodegenerative diseases. Indeed, altered levels of MPs have been described in post-mortem brain samples from PD [14] and AD $[15,16]$ subjects.

Here, we set out to assess the expression of GPR37 in sporadic PD and the presence of ecto-GPR37 peptides in CSF of PD patients. We engineered an in-house immunoassay to assess ecto-GPR37 levels in CSF samples from two different cohorts of PD patients along with age- and gender-matched neurological control (NC) subjects. The CSF ecto-GPR37 levels in AD subjects were also tested.

\section{Methods \\ Antibodies}

The following antibodies were used: rabbit anti-humanGPR37-N polyclonal antibody [17], rabbit anti-mouseGPR37-N polyclonal antibody [7, 18], rabbit anti-panGPR37-C polyclonal antibody [18], mouse anti- $\beta$-actin monoclonal antibody (A5316; Sigma-Aldrich, St. Louis, MO) and rabbit anti- $\alpha$-actinin polyclonal antibody (Santa Cruz Biotechnology Inc., Dallas, TX).

\section{Human post-mortem brain samples}

Human post-mortem brain tissues and CSF samples were obtained from the Institute of Neuropathology HUB-ICO-IDIBELL Biobank and the Hospital ClinicIDIBAPS Biobank following the guidelines of Spanish legislation on this matter (Real Decreto de Biobancos $1716 / 2011)[19,20]$ and upon approval of the local ethics committees. The pathological cases were categorized as PD (LB disease pathology) or AD (neurofibrillary tangle $[\mathrm{NFT}]$ pathology) at stages $1-6$ according to the nomenclature of Braak et al. [21, 22]. The post-mortem delay (PMD) between death and tissue processing was between $2.5 \mathrm{~h}$ and $20.35 \mathrm{~h}$. One hemisphere was immediately cut into 1 -cm-thick coronal sections, and selected areas of the encephalon were rapidly dissected, frozen on metal plates over dry ice, placed in individual airtight plastic bags and stored at $-80{ }^{\circ} \mathrm{C}$ until use for biochemical studies. The other hemisphere was fixed by immersion in $4 \%$ buffered formalin for 3 weeks for morphological studies. The neuropathological diagnosis of all cases was made based on the evaluation of 20 selected de-waxed paraffin sections containing regions of the cerebral cortex, diencephalon, thalamus, brain stem and cerebellum, which were stained with haematoxylin, eosin and Klüver-Barrera. Only cases categorized as stages 3, 4, 5 and 6 (i.e. PD or AD stage 3-6) were considered. Cases with concomitant tauopathies with NFT and $A-B$ stages of $A \beta$ plaque [22] were excluded from the present study. The middle-aged control cases had not suffered from neurologic, psychiatric, or metabolic diseases (including metabolic syndrome), and did not have abnormalities in the neuropathological examination 
excepting stages 1-2 of NFT pathology and phases A-B of $A \beta$ plaques. Cases with associated pathologies such as vascular disease (except mild atherosclerosis and arteriolosclerosis), TDP-43 proteinopathy, infections of the nervous system, brain neoplasm, systemic and central immune diseases, metabolic syndrome and hypoxia were excluded from the present study. The selected brain areas were $\mathrm{SN}$, frontal cortex $(\mathrm{FC})$ and entorhinal cortex (EC), and different series of samples (i.e. NCs, Braak PD/ AD stage 3, Braak PD/AD 4, Braak PD/AD 5 and Braak $\mathrm{PD} / \mathrm{AD}$ 6) were prepared according to their experimental use: (i) PD SN immunoblotting: 5 NCs (3 males and 2 females; mean age: $84.2 \pm 7$ years; PMD: $10.7 \pm 7.7 \mathrm{~h}$ ), 5 Braak PD stage 4 ( 3 males and 2 females; mean age: $77.6 \pm 7.6$ years; PMD: $10.1 \pm 8.2 \mathrm{~h}$ ), 5 Braak PD stage 5 ( 3 males and 2 females; mean age: $80.6 \pm 6.4$ years; PMD: $10.8 \pm 5.2 \mathrm{~h}$ ) and 5 Braak PD stage 6 ( 3 males and 2 females; mean age: $76.2 \pm 7.25$ years; PMD: $9.8 \pm 5.5 \mathrm{~h}$ ) cases; (ii) PD SN RT-qPCR: 10 NCs (8 males and 2 females; mean age: $61.4 \pm 12.8$ years; PMD: $5.7 \pm 3.5 \mathrm{~h}$; RNA integrity number [RIN]: $6.6 \pm 0.4), 7$ Braak PD stage 3/4 (3 males and 4 females; mean age: $78 \pm 5.9$ years; PMD: $5.5 \pm 1.2 \mathrm{~h}$; RIN: $7.2 \pm 0.5)$ and 17 Braak PD stage 5/6 (12 males and 5 females; mean age: $79.8 \pm 4.9$ years; PMD: $8.6 \pm 3.4 \mathrm{~h}$; RIN: $7.1 \pm 0.6$ ) cases; (iii) AD FC RT-qPCR: 17 NCs (10 males and 7 females; mean age: $61.5 \pm 14.4$ years; PMD: $5.1 \pm 1.9 \mathrm{~h}$; RIN: $7.5 \pm 0.6), 9$ Braak AD stage 3/4 (4 males and 5 females; mean age: $78.6 \pm 8.1$ years; PMD: $6.7 \pm 3.5 \mathrm{~h}$; RIN: $7.7 \pm 1)$ and 20 Braak AD stage 5/6 (9 males and 11 females; mean age: $80.5 \pm 6.9$ years; PMD: $9.3 \pm 5.8 \mathrm{~h}$; RIN: $7.5 \pm 0.8$ ); and (iv) AD EC RT-qPCR: 5 NCs (4 males and 1 female; mean age: $41.7 \pm 9.7$ years; PMD: $5.5 \pm 0.8 \mathrm{~h}$; RIN: $6.3 \pm$ 0.9 ), 4 Braak AD stage 3/4 (3 males and 1 female; mean age: $80.5 \pm 1$ years; PMD: $6.6 \pm 4.2 \mathrm{~h}$; RIN: $6.2 \pm 0.7)$ and 5 Braak AD stage 5/6 ( 3 males and 2 females; mean age: $79.2 \pm 5.1$ years; PMD: $7.9 \pm 4$ h; RIN: $6.2 \pm 0.8$ ).

\section{Participants}

PD patients were recruited at the movement disorders clinic at Karolinska University Clinic, Huddinge, Sweden. Patients underwent a clinical examination (including ratings of motor, cognitive and psychiatric symptoms) by an experienced neurologist (PS) (Table 1). All the included patients were followed longitudinally and $\mathrm{PD}$ diagnosis, including subsequent responsiveness to dopaminergic therapy, was confirmed before they were included in the CSF analysis. Hence, the PD patients satisfied the clinical diagnosis of PD according to the U.K. Parkinson Disease Society Brain Bank diagnostic criteria. Motor symptoms were evaluated with the Unified Parkinson's Disease Scale (UPDRS) part 3 in the ON state of medication cycle. Non-motor and motor symptoms in daily activities were evaluated with UPDRS part
Table 1 Demographic and clinical characteristics of the study participants. Participants were recruited at the movement disorders clinic at Karolinska University Clinic, Huddinge, Sweden. Patients underwent a clinical examination as described in the Methods section

\begin{tabular}{lll}
\hline & NC & PD \\
\hline Age (years) & $64 \pm 12$ & $64 \pm 11$ \\
Sex (M/F) & $27 / 18$ & $23 / 18$ \\
Disease duration (years) & - & $5.8 \pm 5.5$ \\
UPDRS Total $(n=26)$ & - & $42 \pm 18$ \\
UPDRS III $(n=26)$ & - & $26 \pm 14$ \\
H\&Y score $(n=40)$ & - & $\|$ \\
MoCA $(n=28)$ & - & $23 \pm 5$ \\
HADS $(n=26)$ & - & $14 \pm 8$ \\
LED $(n=28)$ & - & $709 \pm 512$
\end{tabular}

Data are expressed as mean \pm SD except the Hoehn and Yahr (H\&Y) score as median. UPDRS Unified Parkinson's Disease Scale; MoCA Montreal Cognitive Assessment scores; HADS Hospital Anxiety and Depression scale; LED L-dopa equivalent dose

1 and part 2, respectively. UPDRS part 4 was used to measure motor complications [23]. Almost all patients had available scores for Hoehn \& Yahr scale $(n=40)$ assessing motor impairment [24], and 66\% of the patients had available Montreal Cognitive Assessment scores (MoCA, $n=28$ ) evaluating the cognitive impairment [25]. In addition, within the routine visit self-evaluation questionnaires were implemented, including Non-Motor Symptoms Questionnaire $(n=26)$ [26], and Hospital Anxiety and Depression scale $(n=26)$ [27]. Finally, medications were presented as $L$-dopa equivalent doses [28]. Thirteen patients were drug-naïve, de novo, patients at the time of lumbar puncture. Age- and gender-matched control subjects were recruited from routine neurology examinations. Control patients were also recruited at Karolinska University Clinic, Huddinge, Sweden and were diagnosed with benign neurological diagnoses, such as tension headache with no evidence of dementia, no cognitive complaints, no PD or other brain disease, and thus were defined as NCs.

\section{CSF samples}

For preliminary assessment of ecto-GPR37 in humans, we used post-mortem CSF samples from eight PD pathological cases (six males and two females, mean age: $71.4 \pm 9.9$ years; post-mortem interval: $6.6 \pm 3.7 \mathrm{~h}$ ) (neuropathology confirmed from Bellvitge Hospital Neuropathology Service, see above) and eight agematched control cases (all male; mean age: $66.8 \pm 5.2$ years; post-mortem interval: $6.4 \pm 2.3 \mathrm{~h}$ ). Subsequently, CSF samples were obtained by lumbar puncture from participants from Karolinska University Clinic, collected into polypropylene-tubes and immediately centrifuged at $1800 \times \mathrm{g}$ at $4{ }^{\circ} \mathrm{C}$ for $10 \mathrm{~min}$ before being stored in 
aliquots of $100 \mu \mathrm{l}$ at $-80^{\circ} \mathrm{C}$ as previously described [29]. Thus, CSF samples from a total of 86 participants $(45$ NCs and 41 PD patients out of whom 12 were drugnaïve) were used in the study.

For the analysis of CSF ecto-GPR37 in AD, NC ( 9 males and 13 females; mean age: $65.7 \pm 6.7$ years) and $\mathrm{AD}$ (10 males and 13 females; mean age: $67.6 \pm 7.9$ years) participants were enrolled at the Department of Neurology, Clinical Dementia Center of Göttingen (Germany). The NC participants were those diagnosed with non-primarily neurodegenerative neurological and psychiatric diseases. AD was diagnosed according to the guideline of the National Institute on Aging-Alzheimer's Association workgroups [30]. All the participants had given consent for the use of their clinical data and CSF for research purposes, and the study was approved by the regional ethics committee for medical research in Stockholm (2011/500-31/1 and 2012/2224-32/4). All procedures followed were in accordance with the ethical standards indicated by the Declaration of Helsinki of 1975, as revised in 2000.

\section{Animals}

C57BL/6 J wild-type $\left(\mathrm{GPR}^{+/+}\right)$and GPR37-KO $\left(\mathrm{GPR}^{-1-}\right)$ male mice (Strain Name: B6.129P2GPR37 $7^{\text {tmlDgen }} / \mathrm{J}$; The Jackson Laboratory, Bar Harbor, ME) at 8 weeks of age were used [7]. Animal protocols were approved by the University of Barcelona Committee on Animal Use and Care. Animals were housed and tested in compliance with the guidelines described in the Guide for the Care and Use of Laboratory Animals [31] and following the European Union directives (2010/63/ EU), Federation for Laboratory Animal Science Associations, and Animal Research: Reporting In Vivo Experiments guidelines. All efforts were made to minimize animal suffering and the number of animals used. All animals were housed in groups of five in standard cages with ad-libitum access to food and water under a 12-h dark/light cycle (starting at $7: 30 \mathrm{AM}$ ) at $22^{\circ} \mathrm{C}$ with $66 \%$ humidity (standard conditions).

\section{Mouse CSF samples}

Mice were anesthetized by intraperitoneal administration of a mixture of ketamine $(100 \mathrm{mg} / \mathrm{kg}$, Merial, Spain)/xylazine $(10 \mathrm{mg} / \mathrm{kg}$, Calier, Spain). The animal was stereotaxically immobilized to facilitate the access to the cisterna magna through a sagittal incision just behind the occiput. CSF $(\sim 10 \mu \mathrm{l})$ was collected by puncturing the cisterna magna with a micro-fine (30G) 3-mL syringe-needle. The CSF samples were frozen immediately on dry ice and kept at $-80^{\circ} \mathrm{C}$ until use.

\section{Human brain extract preparation}

The post-mortem human SN tissue (0.1 g of fresh tissue) was homogenized in ice-cold lysis buffer containing 10 $\mathrm{mM}$ Tris $\mathrm{HCl}, 1 \mathrm{mM}$ EDTA, $300 \mathrm{mM} \mathrm{KCl} \mathrm{(pH} \mathrm{7.4)} \mathrm{and} \mathrm{a}$ protease inhibitor cocktail (Roche Molecular Systems, Pleasanton, CA) using a Polytron for $3 \times 10 \mathrm{~s}$ on ice. The homogenate was centrifuged at $1000 \times \mathrm{g}$ for $10 \mathrm{~min}$ at $4{ }^{\circ} \mathrm{C}$. The resulting supernatant was centrifuged at 12 , $000 \times \mathrm{g}$ for $30 \mathrm{~min}$ at $4{ }^{\circ} \mathrm{C}$. The resulting pellet was dispersed in $50 \mathrm{mM}$ Tris $\mathrm{HCl}(\mathrm{pH} 7.4)$ and $10 \mathrm{mM} \mathrm{MgCl}_{2}$, washed, and resuspended in the same medium. Protein concentration was determined using the bicinchoninic acid (BCA) protein assay kit (ThermoFisher Scientific) and $50-80 \mu \mathrm{g}$ of protein was used for immunoblotting.

\section{Gel electrophoresis and immunoblotting}

Brain proteins were separated by sodium dodecylsulfatepolyacrylamide gel electrophoresis (SDS-PAGE) and then transferred to polyvinylidene difluoride membranes using the Trans-Blot ${ }^{\circ}$ Turbo $^{\text {Tax }}$ transfer system (Bio-Rad) at $25 \mathrm{mV}$ for $30 \mathrm{~min}$. Non-specific binding was blocked by incubation with $5 \%$ milk in PBS containing $0.05 \%$ Tween for $1 \mathrm{~h}$ at room temperature. After washing, the membranes were incubated at $4{ }^{\circ} \mathrm{C}$ overnight with the indicated primary antibody in PBS containing 5\% milk and $0.05 \%$ Tween. Then the membranes were incubated for $1 \mathrm{~h}$ with the appropriate horseradish peroxidase (HRP)-conjugated secondary antibody and the immunecomplexes were revealed with a chemiluminescence reagent (ECL, Amersham, GE Healthcare, Buckinghamshire, UK) using an Amersham Imager 600 (GE Healthcare Europe $\mathrm{GmbH}$, Barcelona, Spain). The gel protein loading was assessed by using the rabbit anti- $\alpha-$ actinin polyclonal antibody $(1 \mu \mathrm{g} / \mathrm{ml})$. Protein bands were quantified by densitometric scanning and analysed with the Image J program (National Institutes of Health, Bethesda, MA).

\section{RNA purification and reverse transcription}

RNA was extracted from human post-mortem SN, FC or EC tissues using the RNeasy Lipid Tissue Mini Kit (Qiagen, Hilden, Germany) following the manufacturer's protocol, in combination with DNase digestion to avoid extraction and later amplification of genomic DNA. The concentration of each sample was determined by absorbance at $260 \mathrm{~nm}$ using a NanoDrop 2000 spectrophotometer (ThermoFisher Scientific). RNA integrity was determined using the Agilent 2100 BioAnalyzer (Agilent, Santa Clara, CA). Special care was taken to assess premortem and post-mortem factors, which may interfere with RNA processing [32]. Bivariate analyses were carried out to detect the association of our variables with potential confounding factors (age, PMD and RIN) using Spearman or Pearson correlations for quantitative 
variables. PMD had no effect on RIN values in the present post-mortem samples used (data not shown).

Reverse transcription of the RNA samples was carried out with the High-Capacity cDNA Archive kit (Applied Biosystems, Foster City, CA) and the Gene Amp 9700 PCR System thermocycler (Applied Biosystems). A parallel reaction for an RNA sample was processed in the absence of reverse transcriptase to rule out DNA contamination.

\section{qPCR}

Real-time quantitative PCR (RT-qPCR) assays were conducted in duplicate on 1000 ng of cDNA samples obtained from the reverse-transcription reaction, diluted at 1:20 in 384-well optical plates (Kisker Biotech, Steinfurt, GE), using the ABI Prism 7900 HT Sequence Detection System (Applied Biosystems). Parallel amplification reactions were carried out using 20× TaqMan Gene Expression Assays and $2 \times$ TaqMan Universal PCR Master Mix (Applied Biosystems). $\beta$-Glucuronidase (GUS- $\beta$; Ref: Hs00939627_m1), X-prolyl aminopeptidase (aminopeptidase P) 1 (XPNPEP1, Ref: Hs00958026_m1), alanyltransfer RNA synthase (AARS, Ref: Hs00609836_m1) and hypoxanthine-guanine phosphoribosyltransferase (HPRT, ref: Hs02800695_m1) were used as housekeeping genes for normalization of GPR37 (Ref: Hs00173744 $\mathrm{m} 1$ ) expression. The selection of these housekeeping genes was based on previous data showing low vulnerability in the brains of several human neurodegenerative diseases $[32,33]$. The RT-qPCR reactions were performed at $50^{\circ} \mathrm{C}$ for $2 \mathrm{~min}, 95^{\circ} \mathrm{C}$ for $10 \mathrm{~min}$, and $40 \mathrm{cy}$ cles of $95^{\circ} \mathrm{C}$ for $15 \mathrm{~s}$ and $60^{\circ} \mathrm{C}$ for $1 \mathrm{~min}$. TaqMan PCR data were captured using the Sequence Detection Software (SDS version 2.2, Applied Biosystems). Subsequently, the threshold cycle (CT) data for each sample were analyzed with the $\Delta \Delta C T$ method. First, $\Delta C T$ values were calculated as the normalized $\mathrm{CT}$ values for each target gene in relation to the mean values of GUS- $\beta$, $X P N P E P 1, A A R S$ and $H P R T$. Second, the $\triangle \triangle C T$ values were obtained by the $\triangle C T$ of each sample minus the mean $\triangle \mathrm{CT}$ of the population of control samples (calibrator samples). The fold-change was determined using the eq. $2^{-\Delta \Delta \mathrm{CT}}$.

\section{Generation of the ecto-GPR37 constructs}

The human and mouse GPR37 were tagged at its Nterminal tail with either NanoLuc (NL) luciferase or the $\mathrm{O}^{6}$-alkylguanine-DNA alkyltransferase (AGT) to allow further luminescence or AGT substrate (i.e. SNAP tag) detection, respectively. In addition, an haemagglutinin (HA) epitope was also inserted to allow HA-based purification from cells expressing the corresponding constructs. First, the HA-epitope cDNA sequence was inserted into the pNFL1-secN plasmid (Promega,
Madison, WI) using the QuikChange II Site-Directed Mutagenesis Kit (Stratagene, San Diego, CA) and the following primer pairs: FNLHA: (5'-GCCGGATTAT GCGGCGATCGCTTCCGAATTCAGAGCTCAAC-3') and RNLHA (5'-ACATCATACGGATAGCCGCT CGAGCCCGCCAG-3'). Subsequently, the cDNA encoding mouse GPR37 was amplified by PCR using the primers FNLEcoRVGPR37 (5'-AAACAGATATCTGCT GCCCTGAGCTTTGTCCCT-3') and RNotINLmGPR37 (5'-AAGCGGCCGCTCAGCAATGAGTCCCCAC-3').

The amplified mouse GPR37 insert was then cloned into

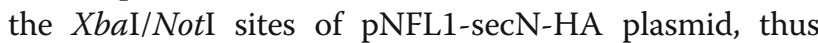
providing the pNFL-HA-mGPR $37^{\mathrm{NL}}$ construct. Similarly, the human GPR37 was amplified using the primers FNLXbaIhGPR37 (5'-AAACATCTAGAGCCCTCGG GGTCGCCCCT-3') and RNLNotIhGPR37 (5' CGAGCGGCCGCTCAGCAATGAGTTCCGACAG-3') and the amplified human GPR37 insert was cloned into the EcoRV/NotI sites of pNFL1-secN-HA plasmid to provide the pNFL-HA-hGPR $37^{\mathrm{NL}}$ construct. Finally, the pRK5-HA-mGPR37 ${ }^{\text {SNAP }}$ and pRK5-HA-hGPR37 ${ }^{\text {SNAP }}$ constructs were obtained by amplifying mouse GPR37 with primers FpRK5EcoRVmGPR37 (5' -AAACAGATA TCGCTGCCCTGAGCTTTGTCCCT-3') and RNo$\overline{t I N L m G P R 37}$ (5' -AAGCGGCCGCTCAGCAATGA GTCCCCAC-3'), and human GPR37 with primers FpRK5XhoImGPR37 (5' -AAACACTCGAGGCCCTCGG GGTCGCCCCT-3') and RNLNotImGPR37 (5' CGAGCGGCCGCTCAGCAATGAGTTCCGACAG-3'). The amplified mouse or human GPR37 insert was then cloned into the EcoRV/NotI and XhoI/NotI sites of pRK5-HA plasmid, thus providing the pRK5-HAmGPR $37^{\text {SNAP }}$ and the pRK5-HA-hGPR37 $7^{\text {SNAP }}$ constructs, respectively. All the constructs were verified by DNA sequencing.

\section{Cell culture and ecto-GPR37 recombinant protein production}

Human embryonic kidney (HEK)-293 T cells (American Type Tissue Culture, Manassas, VA) were grown in Dulbecco's modified Eagle's medium (DMEM) (Sigma-Aldrich) supplemented with $1 \mathrm{mM}$ sodium pyruvate, 2 $\mathrm{mM} L$-glutamine, $100 \mathrm{U} / \mathrm{ml}$ streptomycin, $100 \mathrm{mg} / \mathrm{ml}$ penicillin and $5 \%(v / v)$ fetal bovine serum at $37^{\circ} \mathrm{C}$ in an atmosphere of $5 \% \mathrm{CO}_{2}$. Cells were passaged at $80-90 \%$ confluency.

HEK-293 T cells grown on 10-cm culture dishes were transiently transfected with the pNFL-HA-mGPR $37^{\mathrm{NL}}$, pNFL-HA-hGPR37 ${ }^{\mathrm{NL}}, \quad$ pRK5-HA-mGPR37 ${ }^{\text {SNAP }}$ or pRK5-HA-hGPR37 ${ }^{\text {SNAP }}$ construct using the polyethylenimine method [34]. After $24 \mathrm{~h}$, the culture medium was replaced with DMEM and the supernatant was collected $48 \mathrm{~h}$ and $72 \mathrm{~h}$ after transfection. For purification of the expressed recombinant proteins, the supernatant was 
first centrifuged at $1000 \times \mathrm{g}$ for $5 \mathrm{~min}$ to remove cell debris, and then concentrated and dialysed in Tris-buffered saline (TBS, $50 \mathrm{mM}$ Tris-Cl, $150 \mathrm{mM} \mathrm{NaCl}, \mathrm{pH} 7.5$ ) using an Amicon-Ultra-15 $10 \mathrm{~K}$ falcon tube (Merck, Darmstadt, Germany) upon continuous centrifugation at $3000 \times \mathrm{g}$ at $4{ }^{\circ} \mathrm{C}$ until red phenol was not observed. Subsequently, the supernatant was incubated with Pierce ${ }^{\mathrm{Tx}}$ anti-HA agarose $(1 \mathrm{ml}$, ThermoFisher Scientific, Inc., Rockford, IL) in an end-over-end rotator overnight at $4{ }^{\circ} \mathrm{C}$. After packing and washing the resin with TBS, the recombinant proteins were eluted with glycine- $\mathrm{HCl} \mathrm{pH}$ 2.5 , collected in $1 \mathrm{ml}$ fractions and rapidly neutralized with Tris-base ( $\mathrm{pH}$ 8.8). Fractions containing the purified recombinant proteins (i.e. $\mathrm{mGPR} 37^{\mathrm{NL}}$, hGPR $37^{\mathrm{NL}}$, mGPR $37^{\text {SNAP }}$ or hGPR $37^{\text {SNAP }}$ ) were analysed by immunoblot and the luminescence of NL-containing constructs was determined. Finally, the purified proteins were concentrated 40-fold using an Amicon-Ultra-4 $3 \mathrm{~K}$ falcon tube (Merck) upon continuous centrifugation at $4000 \times \mathrm{g}$ at $15^{\circ} \mathrm{C}$, and then diluted (1:100) in a buffer containing $10 \mathrm{mM}$ Tris- $\mathrm{HCl}$ and $150 \mathrm{mM} \mathrm{NaCl}, \mathrm{pH} 7.4$ in a total volume of $400 \mu$ l, before being quantified by Micro BCA ${ }^{\mathrm{Th}}$ Protein Assay Kit (ThermoFisher Scientific) and Flamingo (Bio-Rad, Hercules, CA) fluorescent protein gel staining.

\section{NL-based enzyme-linked immunosorbent assay (ELISA) for Ecto-GPR37}

CSF ecto-GPR37 was measured with the home-made competitive ELISA method. In brief, streptavidinecoated 96-well white plates (ThermoFisher Scientific) were blocked with serum-free DMEM medium $(100 \mu \mathrm{l} /$ well) for $1 \mathrm{~h}$ at $22^{\circ} \mathrm{C}$. After washing $(3 \times 1 \mathrm{~min})$ with ELISA buffer $(25 \mathrm{mM}$ Tris base, $150 \mathrm{mM} \mathrm{NaCl}, 0.1 \%$ BSA, $0.05 \%$ Tween-20, pH 7.2), the wells were coated with $100 \mu \mathrm{l}$ of anti-rabbit IgG-biotin antibody $(10 \mu \mathrm{g} / \mathrm{ml}$, Sigma Aldrich) in the ELISA buffer for $2 \mathrm{~h}$ at $22^{\circ} \mathrm{C}$. Subsequently, the plates were washed with the ELISA buffer $(3 \times 1 \mathrm{~min})$ and incubated with rabbit anti-GPR37 (mouse) or rabbit anti-GPR37 (human) antibody $(1 \mu \mathrm{g} /$ $\mathrm{ml}$ in ELISA buffer) for $2 \mathrm{~h}$ at $22^{\circ} \mathrm{C}$. Then, $3 \mu \mathrm{l}$ of either mouse or human CSF was added to each well containing $47 \mu \mathrm{l}$ of ELISA buffer and incubated overnight at $4{ }^{\circ} \mathrm{C}$ in a humid chamber. Next day, the plates were washed (3 times, 1 min each) with ELISA buffer and incubated with $50 \mu \mathrm{l}$ of purified ecto-GPR37 ${ }^{\mathrm{NL}}$ (mouse) or ectoGPR37 ${ }^{\mathrm{NL}}$ (human) (50.000 relative light units [RLU]/ $\mu \mathrm{l}$ in ELISA buffer) for $1 \mathrm{~h}$ at $22^{\circ} \mathrm{C}$ in the dark. Finally, the plates were washed $(3 \times 1 \mathrm{~min})$ with ELISA buffer and $90 \mu \mathrm{l}$ of ELISA buffer was added to each well before incorporating $10 \mu \mathrm{l}$ of ELISA buffer solution containing $10 \mu \mathrm{M}$ coelenterazine 400a (NanoLight Technologies, Pinetop, AZ). After 1-min incubation, the end-point luminescence was determined using a CLARIOstar
Optima plate-reader (BMG Labtech $\mathrm{GmbH}$, Ortenberg, Germany) and the output luminescence was reported as the integral RLU. In addition, a standard curve was generated using known concentrations of either mouse or human ecto-GPR37 ${ }^{\text {SNAP }}$ in each experiment.

\section{a-Synuclein ELISA}

The $\alpha$-synuclein concentration was measured using the LEGEND MAX ${ }^{\mathrm{Tm}}$ Human $\alpha$-Synuclein ELISA Kit (844101, BioLegend, San Diego, CA) according to the manufacturer's instructions. Briefly, a microtiter plate pre-coated with the capture antibody was washed 4 times, added with $20 \mu \mathrm{l}$ of CSF at 1:10 dilution in reagent buffer, and incubated overnight at $4{ }^{\circ} \mathrm{C}$ with shaking. Next day, the plate was washed 4 times, followed by addition of the biotinylated detection antibody to each well and incubation for $2 \mathrm{~h}$ at room temperature (RT). The unbound detection antibody was removed by 4 washes. The streptavidin-HRP conjugate was added to each well, incubated for $1 \mathrm{~h}$ at RT and then the plate was washed 4 times to remove the remaining conjugate. Finally, chemiluminescent substrate was added to each well and signals were read using a Tecan Spark $10 \mathrm{M}$ plate reader (Tecan Nordic AB, Stockholm, Sweeden).

\section{Statistical analysis}

Data are presented as mean \pm standard error of mean (SEM) and were analysed by Student's $t$ test or one-way analysis of variance (ANOVA) with Dunnett's post-hoc test using GraphPad Prism 6.01 (San Diego, CA). $P<$ 0.05 was considered as statistically significant. The distribution of CSF ecto-GPR37 did not follow Gaussian distribution (Shapiro-Wilk normality test, $P<0.05$ ), so the data were analysed with non-parametric Mann-Whitney U-tests. The diagnostic accuracy by CSF ecto-GPR37 levels was assessed using the receiver operating characteristic (ROC) curve analysis. The correlation coefficients (rho) were calculated using the Spearman two-tailed correlation test.

\section{Results}

GPR37 density in post-mortem SN from NC and PD subjects

Metalloprotease-mediated GPR37 N-terminus cleavage leads to ectodomain shedding in a heterologous expression system [13]. This posttranslational modification, together with $\mathrm{N}$-glycosylation, generates a heterogenous pattern of GPR37 species that can be detected by immunoblotting, namely the precursor, the full-length mature and some $\mathrm{N}$-terminus-cleaved receptor forms [13]. Here, we first assessed GPR37 density in human SN by immunoblotting using a specific antibody against human GPR37 C-terminal domain (anti-GPR37-C) [18]. The immunoblotting results revealed a wide-range of GPR37 
protein bands (Fig. 1a) compatible with the putative precursor $(67 \mathrm{kDa})$, the full-length mature $(93 \mathrm{kDa})$ and several GPR37 N-terminus-cleaved forms $(76 \mathrm{kDa}, 52 \mathrm{kDa}$, $47 \mathrm{kDa}, 43 \mathrm{kDa}$ and $39-40 \mathrm{kDa}$ ) already described [13]. This is consistent with a recent report of band pattern using a commercial anti-GPR37 C-terminal-domain antibody (RRID: AB_2799658) (https://www.cellsignal. com/products/primary-antibodies/gpr37-d4c8h-rabbit$\mathrm{mab} / 64407)$. These results indicate that in human native tissues (e.g. SN), GPR37 may be N-terminally processed, thus suggesting the existence of a heterogenous pattern of GPR37 species.

GPR37 accumulates in SN LBs of PD patients [35], thus we next assessed the density of the different $\mathrm{N}$ terminally processed forms of GPR37 in SN of PD subjects. The GPR37 precursor density did not increase throughout the different Braak PD stages assayed, but the $\mathrm{N}$-terminal-cleaved forms were significantly $(P=$ 0.0057) increased at Braak PD stage 6 (Fig. 1b), rendering an average of $214 \% \pm 42 \%$ increase of density ( $P=$ 0.0462) when all the GPR37 forms (i.e. precursor plus $\mathrm{N}$-terminus cleaved forms) were considered (Fig. 1b). These results indicated an overall increased density of GPR37 in SN of PD subjects, particular the N-terminalcleaved forms of the receptor. Moreover, RT-qPCR analysis showed a significant $(P=0.0011) 3.1$-fold increase in GPR37 mRNA expression in SN of Braak PD stage 5/ 6 subjects as compared to the NC subjects (Fig. 1c). Collectively, these results confirmed an upregulation of
GPR37 expression in sporadic PD and a concomitant increase in N-terminally cleaved forms of GPR37.

\section{Ecto-GPR37 in CSF}

To test if GPR37 shedding also occurs in native tissue, we monitored GPR37 in vivo shedding by detecting the excised N-terminus of GPR37 (i.e. ecto-GPR37) in the CSF. To confirm the identity of ecto-GPR37 in CSF, we immunoprecipitated ecto-GPR37 using the anti-GPR37$\mathrm{N}$ antibody and the isolated peptides were analysed by liquid chromatography coupled to mass spectrometry (see Supplementary Methods). Six unique peptides corresponding to the $\mathrm{N}$-terminal domain of the human GPR37 in pooled CSF samples from NC and PD patients were detected (Fig. 2). Ecto-GPR37 peptides, especially the EEQGAAFLAGPSWDLPAAPGRDPAAGR peptide, showed an overall increased abundance in CSF from PD patients when compared to that from NC subjects (Fig. 2a). Indeed, these results were consistent with the increased density of $\mathrm{N}$-terminally cleaved forms of the receptor shown in the immunoblot analysis of postmortem SN from PD subjects (Fig. 1a and b).

Subsequently, we developed an in-house speciesspecific NL-based ELISA assay to detect either mouse or human ecto-GPR37 at the extracellular milieu (i.e. CSF). First, we engineered specific mouse or human GPR37 constructs containing $\mathrm{HA}$ and NL tags at the $\mathrm{N}$ terminus (Fig. 3a) to allow their purification and further luminescence detection (Fig. $3 \mathrm{~b}$ and c). The recombinant
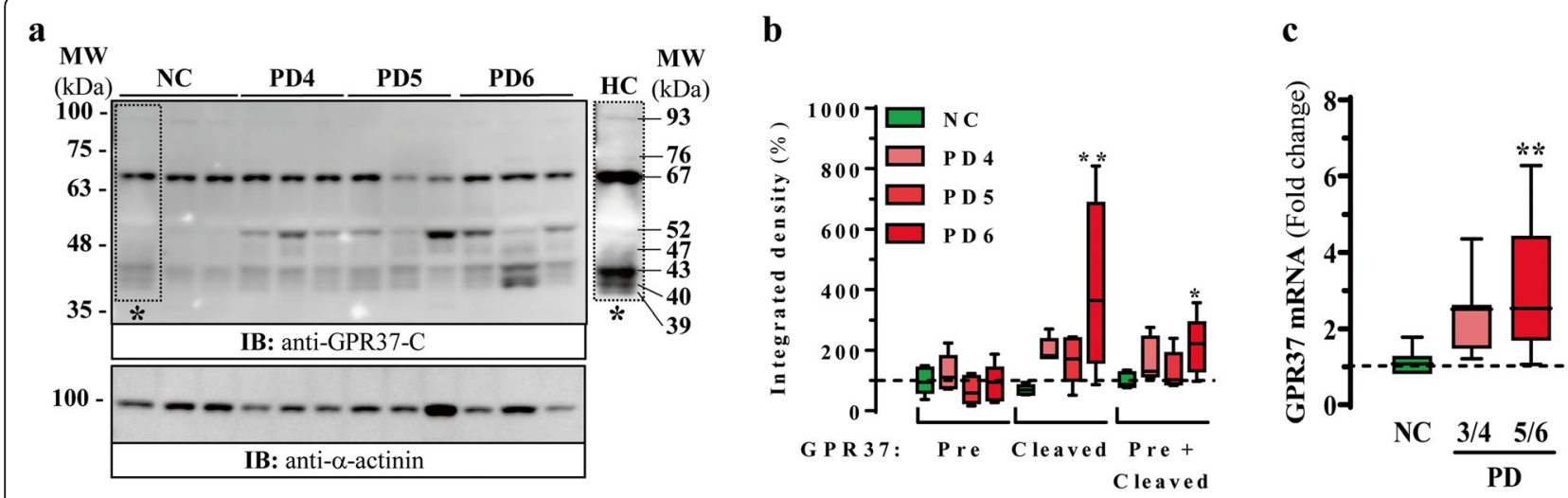

Fig. 1 GPR37 protein density and mRNA levels in post-mortem brain tissues from neurological controls (NCS) and Parkinson's disease (PD) subjects. a Immunoblots showing the expression of GPR37 in the SN of NC and PD subjects (Braak PD stage 4, Braak PD 5 and Braak PD 6). Extracts from the human post-mortem SN were analysed by SDS-PAGE and immunoblotted using rabbit anti-GPR37-C and rabbit anti-a-actinin antibodies. The right dashed outlined area $\left(^{*}\right)$ is shown with enhanced contrast and corresponds to lane 1 (NC). The different GPR37 forms included precursor $(70 \mathrm{kDa}$ ), full-length mature $(93 \mathrm{kDa}$ ) and GPR37 N-terminus-cleaved forms ( $76 \mathrm{kDa}, 52 \mathrm{kDa}, 47 \mathrm{kDa}, 43 \mathrm{kDa}$ and $39-40 \mathrm{kDa})$. b Relative quantification of GPR37 protein density in the SN. The immunoblots corresponding to the precursor (Pre) and cleaved GPR37 forms from the NC $(n=5)$, Braak PD stage $4(n=5)$, Braak PD stage $5(n=5)$ and Braak PD stage $6(n=5)$ subjects were quantified by densitometric scanning. Values were normalized to a-actinin in each lane to correct for protein loading. Results are expressed as the percentage (mean \pm SEM) of the NC. ${ }^{*} P<0.05$, ${ }^{* *} P<0.01$ vs NC, one-way ANOVA followed by Dunnett's post-hoc test. c RT-qPCR assessment of GPR37 mRNA expression in postmortem SN from NCS $(n=10)$, Braak PD stage 3/4 $(n=7)$ and Braak PD stage 5/6 $(n=17)$ subjects. Mean values of the housekeeping genes (GUS$B, X P N P E P 1, A A R S$ and HPRT) were used to normalize samples. Results are expressed as fold-change (mean $\pm \mathrm{SEM}$ ) of the NCs. ${ }^{*} P<0.01 \mathrm{VS} N C$, one-way ANOVA followed by Dunnett's post-hoc test 


\begin{tabular}{|c|c|c|c|}
\hline \multirow{2}{*}{ Peptide (aa) } & \multirow{2}{*}{ Sequence } & \multicolumn{2}{|c|}{ Abundance (XIC) } \\
\hline & & NC & PD \\
\hline 53-64 & GRDAWGPGNSAR & $9.8 \times 10^{6}$ & $1.4 \times 10^{7}$ \\
\hline $55-64$ & DAWGPGNSAR & $2.2 \times 10^{7}$ & $3.2 \times 10^{7}$ \\
\hline 74-100 & EEQGAAFLAGPSWDLPAAPGRDPAAGR & $3.4 \times 10^{6}$ & $1.5 \times 10^{8}$ \\
\hline 74-94 & EEQGAAFLAGPSWDLPAAPGR & NA & $2.1 \times 10^{6}$ \\
\hline $127-136$ & GQEPSETLGR & $4.9 \times 10^{7}$ & $7 \times 10^{7}$ \\
\hline$\because 172-184$ & TVPGASDLFYWPR & NA & N \\
\hline
\end{tabular}

b

$67 \mathrm{kDa}$ MARAPGACLC)

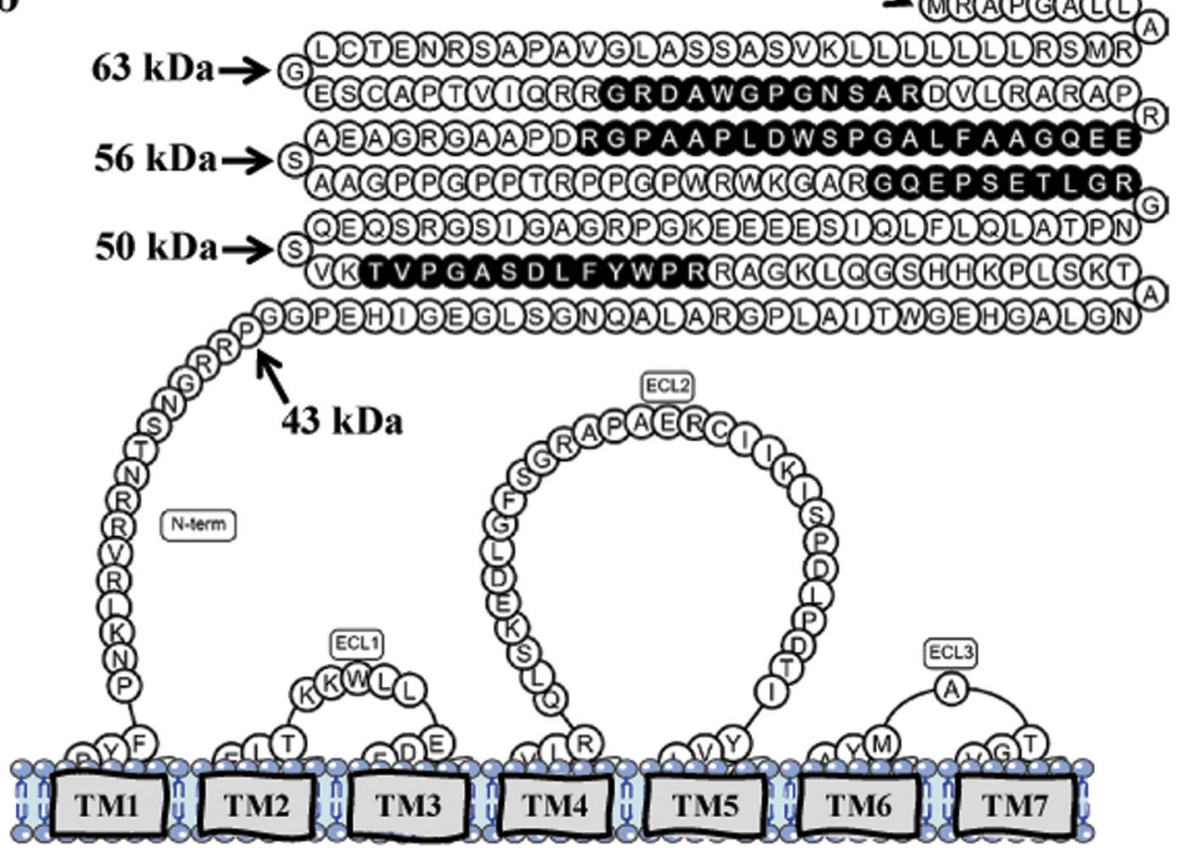

Fig. 2 Ecto-GPR37 peptides detected in human CSF. a Mass spectrometric results (see Supplementary Methods) of human ecto-GPR37 peptides immunoprecipitated from the pooled CSF of NC $(n=10)$ or PD subjects $(n=10)$. The detected peptide sequences in the CSF of NC and PD are indicated $\left(\mathrm{M}+\mathrm{H}^{+}\right)$and their estimated abundance was expressed as the area from the extracted ion chromatograms (XIC) of the peptide chromatographic peak. NA, not quantified. b Schematic representation showing the precise location of the mass spectrometry-detected ectoGPR37 peptides (black circles) within the N-terminal domain (N-term) of the receptor. The theoretical molecular weight (kDa) based on the amino acid sequence of human GPR37 is indicated (arrows). The seven transmembrane (TM) domains of the receptor embedded within the membrane are highlighted in grey. The three extracellular loops (ECL) are also indicated. The GPR37 scheme was made using the GPCRdb resource [36]

mouse or human ecto-GPR37 $7^{\mathrm{NL}}$ protein was used as a tracer in an ELISA assay operated with a rabbit antimouse/human GPR37-N polyclonal antibody captured to microplates coated with an anti-rabbit antibody. Indeed, the sensitivity of the ELISA assay was previously assessed by performing competition assays with recombinant mouse or human ecto-GPR37 ${ }^{\text {SNAP }}$ protein (data not shown). Subsequently, we determined the ectoGPR37 density in mouse and human CSF. First, CSF from wild-type and GPR $37^{-1-}$ mice was assayed with the specific mouse GPR37-NL-based ELISA assay. While significant amount of ecto-GPR37 was detected in the CSF from $\mathrm{GPR} 7^{+/+}$mice, which was determined to be
$286.8 \pm 77.3 \mathrm{pg} / \mathrm{ml}$, ecto-GPR37 was undetectable in all CSF volumes from the GPR37 $7^{-1-}$ mice assayed (Fig. 3d). These results indicate that the specific mouse ectoGPR37 ELISA assay unequivocally detected ecto-GPR37 in the mouse CSF.

Next, we analysed post-mortem human CSF from a small cohort $(n=8)$ of $\mathrm{NC}$ and PD subjects using the specific human GPR37 NL-based ELISA assay. While the NCs had an average ecto-GPR37 content of $185 \pm$ $17 \mathrm{pg} / \mathrm{ml}$ in the CSF, the PD patients had $282 \pm 18 \mathrm{pg} / \mathrm{ml}$ ecto-GPR37 in the CSF. Thus, ecto-GPR37 was significantly $(P=0.019)$ increased in the CSF of PD patients (Fig. 3e). Subsequently, a larger and different cohort of 

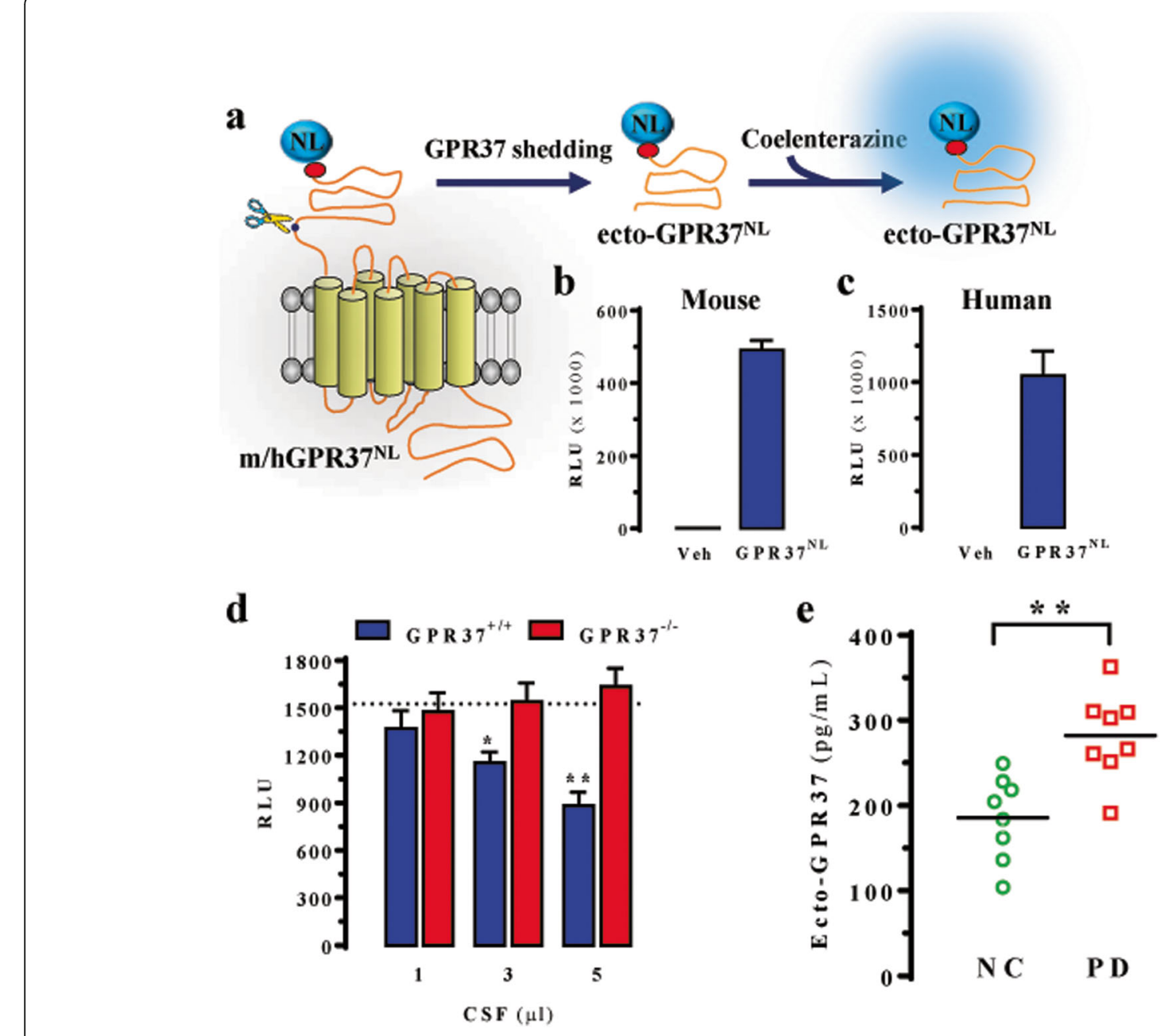

Fig. 3 Detection of ecto-GPR37 by the NanoLuc (NL)-based immunoassay. a Schematic representation showing the putative metalloproteinase (scissors)-mediated cleavage and shedding of the GPR37 N-terminal domain (i.e. ecto-GPR37) in a GPR37 construct containing the HA (filled red circle) and NL tags at its N-terminus (i.e. ecto-GPR3 $7^{\mathrm{NL}}$ ). Upon expression in HEK-293 cells, the GPR37 $7^{\mathrm{NL}}$ ectodomain was released by shedding and detected in the culture medium by monitoring its NL enzymatic activity after incubation of the growth medium of cells transfected with mock (Veh) or mouse (b)/human (c) GPR37 ${ }^{\mathrm{NL}}$ with coelenterazine 400a and determination of the luminescence (RLU, relative light units). $\mathbf{d}$ Assessment of ecto-GPR37 in $1 \mu \mathrm{l}, 3 \mu \mathrm{l}$ and $5 \mu \mathrm{l}$ of cerebrospinal fluid of GPR37 $7^{+/+}$and GPR37 $7^{-1-}$ mice. The purified mouse ecto-GPR3 $7^{\mathrm{NL}}$ was used as a tracer in the competitive ELISA. Results are expressed as RLU (mean $\pm S D, n=3$ ). Dashed line represents the RLU max (i.e. RLU in the absence of CSF). ${ }^{*} P<0.05$ and ${ }^{* *} P<0.01$ vs RLU max, one-way ANOVA followed by Dunnett's post-hoc test. e Assessment of ecto-GPR37 in post-mortem CSF from NC $(n=8)$ and PD $(n=8)$ subjects from Bellvitge Hospital using the GPR37-NL-based ELISA assay. ${ }^{* *} P<0.01$, Student's t-test

$\mathrm{NC}(n=45)$ and PD $(n=41)$ subjects was assayed. Again, significantly higher levels of CSF ecto-GPR37 were found in the PD subjects $(334 \pm 28 \mathrm{pg} / \mathrm{ml})$ when compared to the NCs $(159 \pm 21 \mathrm{pg} / \mathrm{ml})(P=0.001)$ (Fig. 4a). ROC curve analysis demonstrated that the human GPR37 NL-based ELISA assay could differentiate PD subjects $(n=41)$ from NCs $(n=45)$, with the area under the curve (AUC) of $0.808 \quad(0.713-0.900) \quad(P<0.0001)$ (Fig. 4b). The assay, with a cut-off value of $200 \mathrm{pg} / \mathrm{ml}$, had a sensitivity of $73 \%$, a specificity of $73 \%$, a positive predictive value of $71 \%$, and a negative predictive value of $75 \%$ for PD diagnosis (Fig. 4b). In addition, no statistically significant correlations between age/gender and CSF
ecto-GPR37 levels were observed in neither the NC nor the PD group (Fig. S1). Also, there were no correlations between the ecto-GPR37 levels in the PD group and the main clinical features monitored (Table 1, Fig. S2).

Since $\alpha$-synuclein has attracted considerable attention as a potential molecular biomarker for PD, we analysed the $\alpha$-synuclein content in the CSF of the same PD cohort (Table 1). No significant difference in the total $\alpha$ synuclein concentration in the CSF was found between the NC and PD subjects $(1049 \pm 39 \mathrm{pg} / \mathrm{ml}$ vs $1061 \pm 37$ $\mathrm{pg} / \mathrm{ml}, P=0.4692$ ) (Fig. 4c). The corresponding ROC curve analysis showed that the $\alpha$-synuclein ELISA assay could not discriminate between the NC and PD subjects 


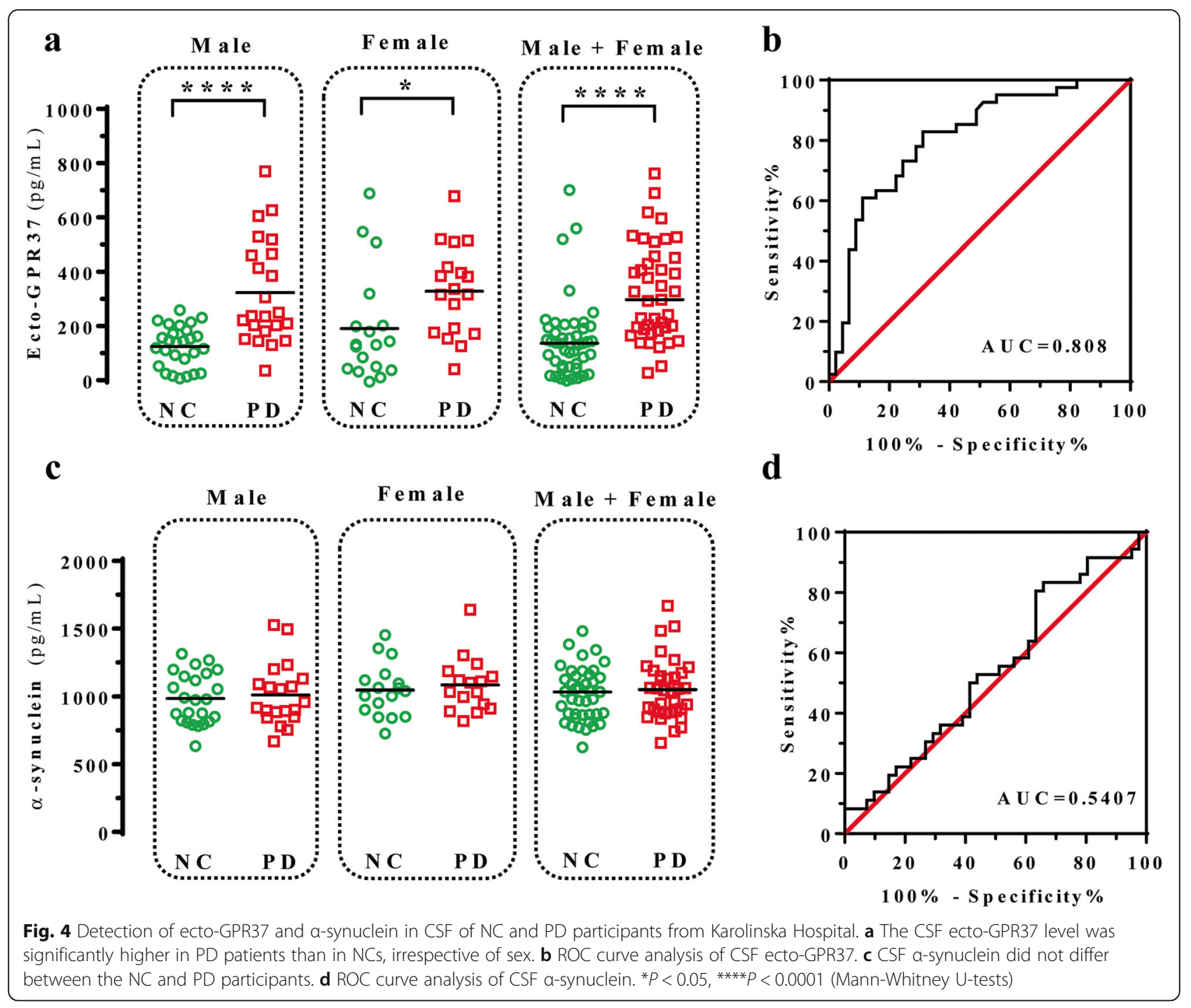

(AUC $=0.5407, P=0.5402$ ) (Fig. 4d). Overall, the results suggested that the CSF total $\alpha$-synuclein could not distinguish PD patients from control subjects.

Last, we assessed whether the CSF ecto-GPR37 had a specific role in the diagnosis of $\mathrm{AD}$, the most common neurodegenerative disorder. To this end, we first evaluated GPR37 mRNA expression levels in the FC and EC from $\mathrm{NC}$ and Braak $\mathrm{AD}$ stage $3 / 4$ and $5 / 6$ subjects (AD3/4 and AD5/6, respectively) by RT-qPCR. There were no significant changes in GPR37 mRNA expression in either $\mathrm{FC}$ or $\mathrm{EC}$ among $\mathrm{NC}, \mathrm{AD} 3 / 4$ and $\mathrm{AD} 5 / 6$ subjects (Fig. 5a and b). Subsequently, we evaluated the ecto-GPR37 content in the CSF from NC and AD patients using the GPR37 NL-based ELISA assay, and found no significant difference between the NC (203 \pm $42 \mathrm{pg} / \mathrm{ml})$ and $\mathrm{AD}(304 \pm 61 \mathrm{pg} / \mathrm{ml})$ subjects $(P=0.1266$; Fig. 5c). The corresponding ROC curve analysis showed that the human GPR37 NL-based ELISA assay could not discriminate between the $\mathrm{NC}$ and $\mathrm{AD}$ subjects $(\mathrm{AUC}=$
0.6107, $P=0.2036$ ) (Fig. 5d). Although PD and AD pathologies share impaired biological processes, our results suggest a differential molecular mechanism of GPR37 expression and CSF ecto-GPR37 levels between AD and PD. Thus, further studies are required to characterize GPR37 biology in AD.

\section{Discussion}

Although GPR37 has been postulated to be the receptor for the neuroprotective and glioprotective factors prosaptide and prosaposin $[37,38]$, the precise physiological function of the receptor remains elusive. Recent studies have reported some alternative functions of GPR37, such as the chaperone-like activity that controls the cell surface targeting and function of adenosine and dopamine receptors [18, 39], and participation in the Wnt coreceptor LRP6 maturation [40]. Remarkably, it has been demonstrated that the GPR37 N-terminus is processed by MPs, leading to the generation of different GPR37 N- 

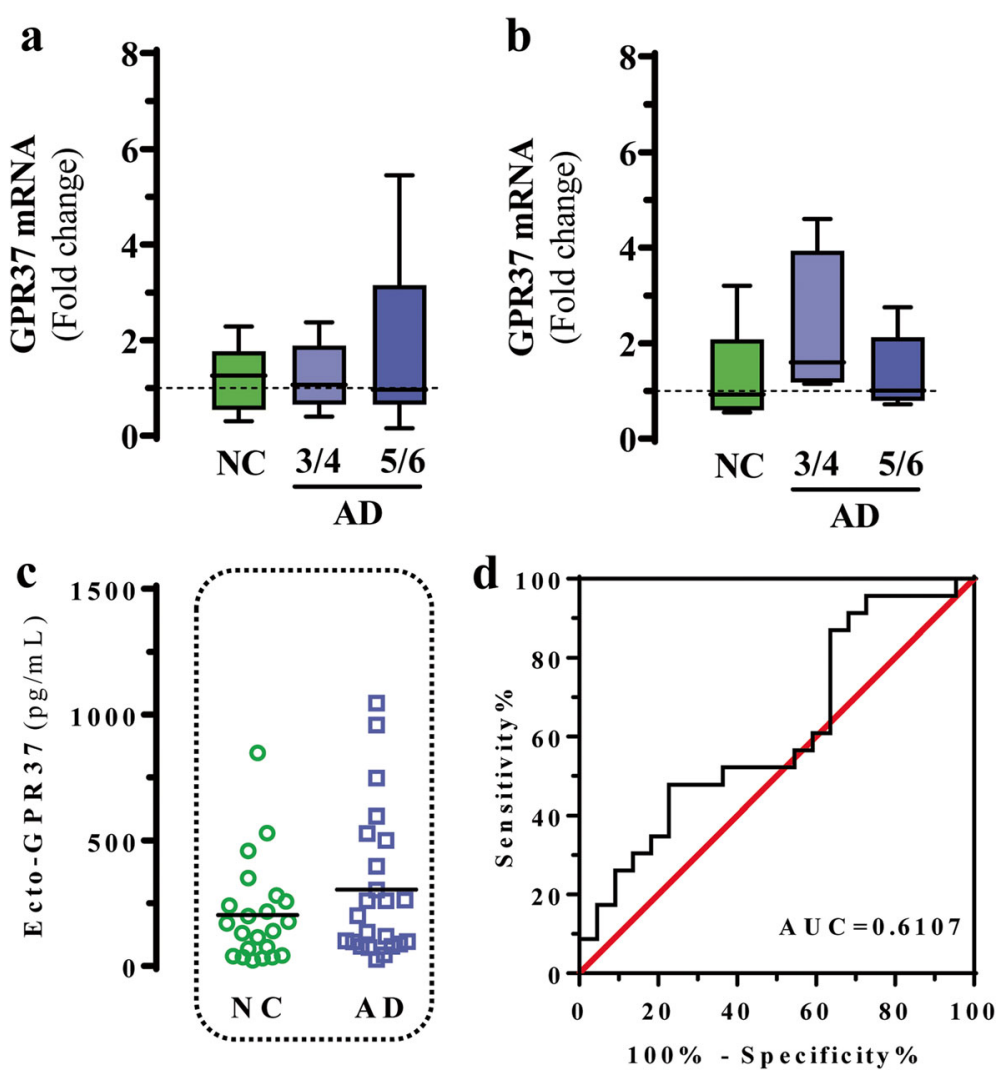

Fig. 5 GPR37 mRNA expression and ecto-GPR37 levels in AD. GPR37 mRNA expression in post-mortem frontal cortex (a) and entorhinal cortex (b) from NCs (panel a: $n=17 ; \mathbf{b}: n=5)$, Braak AD stage $3 / 4(\mathbf{a}: n=9 ; \mathbf{b}: n=4)$ and Braak AD stage $5 / 6(\mathbf{a}: n=20 ; \mathbf{b}: n=5)$ subjects was assessed by RTqPCR. Mean values of the housekeeping genes (GUS-B, XPNPEP1, AARS and HPRT) were used to normalize samples. Results are expressed as foldchange (mean \pm SEM) of the NCs. c Detection of ecto-GPR37 in the CSF from NC $(n=22)$ and AD $(n=23)$ participants recruited at the University Medical School of Göttingen. d ROC curve analysis of CSF ecto-GPR37

terminally cleaved forms [13]. While frequently described in the processing of single-pass membraneanchored proteins, the MP-mediated shedding is less common in post-translational modification of GPCRs [41]. The N-terminal ectodomain of GPR37 has been found to be susceptible to the MP-mediated cleavage, which occurs constitutively in the absence of any external stimulation and leads to the shedding of the receptor $\mathrm{N}$-terminus (i.e. ecto-GPR37). Interestingly, although the GPR37 precursors are efficiently converted into the mature receptor forms (i.e. fully glycosylated forms) and targeted to the plasma membrane, by far most cell surface receptors exist in a cleaved form under steady-state homeostatic conditions. Therefore, it can be speculated that in neurodegenerative conditions which develop with GPR37 overexpression and/or MP alterations, as in PD [14], the ecto-GPR37 levels may mirror the neural damage during disease progression.

In the present study, the presence of ecto-GPR37 peptides in human CSF was first revealed by mass spectrometry. Interestingly, all the ecto-GPR37 peptides found in the CSF of NC subjects (Fig. 2b) corresponded to the $\mathrm{N}$-terminal amino acid sequences upstream the most abundant cleaved form of the receptor (i.e. $43 \mathrm{kDa}$ ) detected in our immunoblot experiments. This observation was compatible with the occurrence of constitutive shedding of the receptor in vivo, thus reinforcing the biological relevance of this process for GPR37. In addition, the immunoblotting detection of GPR37 in PD $\mathrm{SN}$ revealed upregulation of a prominent $52-\mathrm{kDa}$ receptor form, which correlated with the increased CSF density of upstream N-terminal peptides, especially the EEQGAAFLAGPSWDLPAAPGRDPAAGR and GRDA WGPGNSAR peptides. The precise molecular mechanisms underlying the differential GPR37 shedding in PD require further investigation.

The human GPR37 NL-based ELISA assay allowed reproducible measurement of ecto-GPR37 levels in CSF samples. Here, we found significantly higher levels of ecto-GPR37 in the CSF of PD patients compared to that in the NCs in two independent clinical cohorts, consistent with the higher density of CSF ecto-GPR37 peptides revealed by the proteomic analysis. Interestingly, our findings showed that the CSF ecto-GPR37 achieved 
diagnostic performance when the CSF samples from the $\mathrm{PD}$ patients were analyzed and compared to the NC subjects. The finding of no correlations between clinical ratings and the CSF content of ecto-GPR37 in the PD patients may be related to the fact that this part of the study was underpowered. The lack of correlation with the UPDRS motor scores may be because that the clinical ratings were performed when the patients were $\mathrm{ON}$, i.e. they took their daily treatments before the visit to the clinics. In addition, here we found no alterations of the CSF total $\alpha$-synuclein in the same PD cohort, which was consistent with previous reports [42-47]. However, there were also studies reporting lower levels of total $\alpha$ synuclein in the CSF of PD subjects [48]. Other studies have found that the total CSF $\alpha$-synuclein in PD overlaps with that found in different diseases, thus being not possible to discriminate between patients with synucleinopathies and cognitively normal subjects suffering from other non-neurodegenerative diseases [43]. Finally, two meta-analytic reviews of the existing data revealed that the CSF total $\alpha$-synuclein is lower in PD patients compared to controls $[44,45]$. The sensitivity and specificity for distinguishing PD from controls were 0.72 and 0.65 [44] or 0.88 and 0.4 [45], respectively, and the ROC curve showed an AUC of 0.73 [45]. Thus, while the total CSF $\alpha$-synuclein by itself shows a low diagnostic accuracy and does not seem to be a reliable PD diagnostic marker, it may provide a higher accuracy in PD diagnosis when combined with other biomarkers $[4,5]$. Instead, the real-time quaking-induced conversion (RT-QuIC) assay detected $\alpha$-synuclein aggregation in PD CSF with a sensitivity of $95 \%$ and a specificity of $100 \%$ when compared to control CSF [46]. However, RT-QuIC is timeconsuming (several days) and cumbersome to perform. In addition to the CSF biomarkers, DatScan SPECT imaging is clinically used to aid PD diagnosis, and has an AUC value of $0.92-0.96$ in distinguishing PD from controls [47]. However, the DatScan SPECT is expensive and, from the pathological perspective, it does not perform well to predict the number of nigral neurons in PD [48]. Therefore, there is still a need for novel fluid biomarkers of PD that are inexpensive and easy to perform.

Interestingly, here we found no significant increase of CSF ecto-GPR37 in AD patients compared to the NCs. $\mathrm{AD}$ is pathologically characterized by the accumulation of $A \beta$ and pathologically modified tau proteins to form senile plaques and NFTs, respectively [49]. In addition, AD patients often present with accumulation of other proteins including $\alpha$-synuclein and TDP-43, which may play a pathogenic role in $\mathrm{AD}$ and/or reflect the diversity of AD pathophysiology. Thus, biomarkers based on these proteins are widely considered as useful diagnostic markers of AD. The results of CSF ecto-GPR37 in AD suggest different pathological participation of GPR37 in
$P D$ versus $A D$. The differential diagnostic value of GPR37 in PD and AD may be useful for discriminating combined neurodegenerative pathologies, thus allowing correct stratification of these brain disorders, especially at early stage. Further longitudinal studies combining CSF ecto-GPR37 with reliable biomarkers for neurodegenerative diseases are needed. In addition, it would be necessary to explore whether the CSF ecto-GPR37 can be used for the differential diagnosis between PD and atypical parkinsonism, including LB dementia, multiple system atrophy, progressive supranuclear palsy and corticobasal syndrome. Moreover, future studies are needed to elucidate whether the CSF ecto-GPR37 can assist in discriminating the PD patients who will develop a certain phenotype, e.g. PD dementia, and/or those who will have a rapid disease progression.

\section{Conclusion}

In this study, we reported, for the first time, that significantly higher levels of ecto-GPR37 were detectable in the CSF of PD patients. In addition, the CSF ectoGPR37 achieved good diagnostic performance for PD, in contrast to the total $\alpha$-synuclein performance. Interestingly, the ecto-GPR37 levels were not increased in the CSF of AD subjects. Thus, our study provides strong evidence supporting CSF ecto-GPR37 as a promising biomarker of PD. Hence, the CSF ecto-GPR37 levels may evolve into a measurement of PD neuropathology, complementing the existing biomarkers. Future studies should be performed to explore the potential use of ecto-GPR37 in combination with other neurodegeneration-related biomarkers in clinical research, trials and practice.

\section{Supplementary Information}

The online version contains supplementary material available at https://doi. org/10.1186/s40035-021-00232-7.

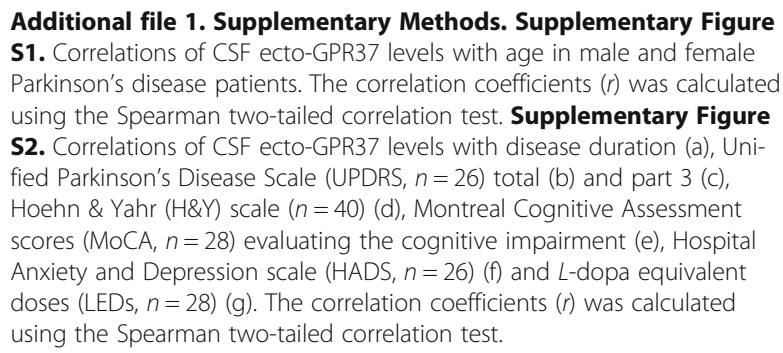

\section{Abbreviations}

PD: Parkinson's disease; AD: Alzheimer's disease; NC: Neurological control; CSF: Cerebrospinal fluid; ELISA: Enzyme-linked immunosorbent assay; GPCR: G protein-coupled receptor; MP: Metalloproteinase; ecto-GPR37: GPR37 ectodomain; NFT: Neurofibrillary tangle; UPDRS: Unified Parkinson's disease scale; MoCA: Montreal cognitive assessment; BCA: Bicinchoninic acid; SDSPAGE: Sodium dodecylsulfate-polyacrylamide gel electrophoresis; HRP: Horseradish peroxidase; RT-qPCR: Real-time quantitative polymerase chain reaction; GUS- $\beta$ : $\beta$-Glucuronidase; XPNPEP1: X-prolyl aminopeptidase P; 
AARS: Alanyl-transfer RNA synthase; HPRT: Hypoxanthine-guanine phosphoribosyltransferase; AGT: $0^{6}$-alkylguanine-DNA alkyltransferase; HA: Haemagglutinin; HEK: Human embryonic kidney; DMEM: Dulbecco's modified Eagle's medium; ROC: Receiver operating characteristic: NL: NanoLuc luciferase; AUC: Area under the curve

\section{Acknowledgements}

We thank Centres de Recerca de Catalunya (CERCA) Programme/Generalitat de Catalunya for IDIBELL institutional support. We thank Esther Castaño and Benjamín Torrejón from the CCiT-Bellvitge Campus of the University of BarceIona, Eliandre de Oliveira from the Proteomic Unit of Parc Científic de BarceIona, and Dr. Xiaoqun Zhang for arranging the cohorts of analyzed CSF samples. Also, we thank the biostatistics unit of Bellvitge Institute for Biomedical Research. Finally, we are indebted to the IDIBAPS Biobank for sample and data procurement

\section{Authors' contributions}

Study conception and design: F.C., U.E.P-R., and V.F-D. Project supervision: F.C., I.F., and V.F-D. Data collection: X.M., P.G-E., J.A., and E.B. Data analysis and interpretation: X.M., I.F., I. Z, F.L., and F.C. Drafting: P.S. and F.C. All authors read and approved the final manuscript.

\section{Funding}

This work was supported by Ministerio de Ciencia, Innovación y Universidades-Agencia Estatal de Investigación/FEDER (SAF2017-87349-R and MDM-2017-0729) and ISCIII/FEDER (PIE14/00034 and PI19/00144), Generalitat de Catalunya (2017SGR1604, 2017SGR595), Fundació la Marató de TV3 (Grant 20152031) and FWO (SBO-140028). ERC consolidator grant (Progsy 649116), Stiftelsen för Strategisk Forkkning and a Wallenberg Clinical Scholarship to PS. The CRG/UPF Proteomics Unit is part of the Spanish Infrastructure for Omics Technologies (ICTS OmicsTech) and is a member of the ProteoRed PRB3 consortium which is supported by grant PT17/0019 of the PE I + D + i 2013-2016 from the Instituto de Salud Carlos III (ISCIII) and ERDF.

\section{Availability of data and materials}

The data that support the findings of this study are available from the corresponding author upon reasonable request.

\section{Ethics approval and consent to participate}

This study was approved by the regional ethics committee for medical research in Stockholm (2011/500-31/1 and 2012/2224-32/4). Animals were housed and tested in compliance with the guidelines described in the Materials and Methods section and all animal protocols were approved by the University of Barcelona Committee on Animal Use and Care (DAAM_7035). The use of human brain biopsies was approved by the Bellvitge Hospital Ethic Committee for Research (BB19_024).

\section{Consent for publication}

Not applicable.

\section{Competing interests}

The authors declare no competing interest relevant to the work conducted in the present study.

\section{Author details}

'Pharmacology Unit, Department of Pathology and Experimental Therapeutics, Faculty of Medicine and Health Sciences, Institute of Neurosciences, University of Barcelona, L'Hospitalet de Llobregat, Spain. ${ }^{2}$ Neuroscience Program, Bellvitge Biomedical Research Institute, IDIBELL, L'Hospitalet de Llobregat, Spain. ${ }^{3}$ Section of Neurology, Department of Clinical Neuroscience, Department of Neuroscience, Karolinska Institute, Stockholm, Sweden. ${ }^{4}$ Neuropathology Unit, Department of Pathology and Experimental Therapeutics, Faculty of Medicine and Health Sciences, Institute of Neurosciences, University of Barcelona, L'Hospitalet de Llobregat, Spain. ${ }^{5}$ CIBERNED, Centro de Investigación Biomédica en Red de Enfermedades Neurodegenerativas, Instituto Carlos III, Madrid, Spain. ${ }^{6}$ Department of Neurology, Clinical Dementia Center and National Reference Center for CJD Surveillance, University Medical School, Göttingen, Germany. ${ }^{7}$ German Center for Neurodegenerative Diseases, Göttingen, Germany. ${ }^{8}$ Proteomics Unit, Center for Genomic Regulation, Barcelona, Spain. ${ }^{9}$ Proteomics Unit,
Universitat Pompeu Fabra, Barcelona, Spain. ${ }^{10}$ Research Unit of Biomedicine, Medical Research Center Oulu, University of Oulu, Oulu, Finland.

\section{Received: 24 November 2020 Accepted: 8 February 2021 Published online: 26 February 2021}

\section{References}

1. de Lau LM, Breteler MM. Epidemiology of Parkinson's disease. Lancet Neurol. 2006:5(6):525-35

2. Cookson MR. The biochemistry of Parkinson's disease. Annu Rev Biochem. 2005;74:29-52.

3. Blennow K, Hampel H, Weiner M, Zetterberg H. Cerebrospinal fluid and plasma biomarkers in Alzheimer disease. Nat Rev Neurol. 2010;6(3):131-44.

4. Parnetti L, Castrioto A, Chiasserini D, Persichetti E, Tambasco N, El-Agnaf O, et al. Cerebrospinal fluid biomarkers in Parkinson disease. Nat Rev Neurol. 2013;9(3):131-40.

5. Parnetti L, Gaetani L, Eusebi P, Paciotti S, Hansson O. El-Agnaf O, et al. CSF and blood biomarkers for Parkinson's disease. Lancet Neurol. 2019;18(6):573-86.

6. Donohue PJ, Shapira H, Mantey SA, Hampton LL, Jensen RT, Battey JF. A human gene encodes a putative $\mathrm{G}$ protein-coupled receptor highly expressed in the central nervous system. Brain Res Mol Brain Res. 1998:54(1): 152-60.

7. Lopes JP, Morató X, Souza C, Pinhal C, Machado NJ, Canas PM, et al. The role of Parkinson's disease-associated receptor GPR37 in the hippocampus: functional interplay with the adenosinergic system. J Neurochem. 2015; 134(1):135-46.

8. Yang HJ, Vainshtein A, Maik-Rachline G, Peles E. G protein-coupled receptor 37 is a negative regulator of oligodendrocyte differentiation and myelination. Nat Commun. 2016;7:10884.

9. Imai Y, Soda M, Inoue H, Hattori N, Mizuno Y, Takahashi R. An unfolded putative transmembrane polypeptide, which can lead to endoplasmic reticulum stress, is a substrate of Parkin. Cell. 2001;105(7):891-902.

10. Kitada T, Asakawa S, Hattori N, Matsumine H, Yamamura Y, Minoshima S, et al. Mutations in the parkin gene cause autosomal recessive juvenile parkinsonism. Nature. 1998;392(6676):605-8.

11. Shimura H, Hattori N, Kubo S, Mizuno Y, Asakawa S, Minoshima S, et al. Familial Parkinson disease gene product, parkin, is a ubiquitin-protein ligase. Nat Genet. 2000;25(3):302-5.

12. Marazziti D, Golini E, Mandillo S, Magrelli A, Witke W, Matteoni R, et al. Altered dopamine signaling and MPTP resistance in mice lacking the Parkinson's disease-associated GPR37/parkin-associated endothelin-like receptor. Proc Natl Acad Sci U S A. 2004;101(27):10189-94.

13. Mattila SO, Tuusa JT, Petäjä-Repo UE. The Parkinson's-disease-associated receptor GPR37 undergoes metalloproteinase-mediated N-terminal cleavage and ectodomain shedding. J Cell Sci. 2016;129(7):1366-77.

14. Lorenzl S, Albers DS, Narr S, Chirichigno J, Beal MF. Expression of MMP-2, MMP-9, and MMP-1 and their endogenous counterregulators TIMP-1 and TIMP-2 in postmortem brain tissue of Parkinson's disease. Exp Neurol. 2002; 178(1):13-20.

15. Duits FH, Hernandez-Guillamon M, Montaner J, Goos JDC, Montañola A Wattjes MP, et al. Matrix Metalloproteinases in Alzheimer's disease and concurrent cerebral microbleeds. J Alzheimers Dis. 2015:48(3):711-20.

16. Leake A, Morris CM, Whateley J. Brain matrix metalloproteinase 1 levels are elevated in Alzheimer's disease. Neurosci Lett. 2000;291(3):201-3.

17. Gandía J, Fernández-Dueñas V, Morató X, Caltabiano G, González-Muñiz R, Pardo L, et al. The Parkinson's disease-associated GPR37 receptor-mediated cytotoxicity is controlled by its intracellular cysteine-rich domain. J Neurochem. 2013;125(3):362-72.

18. Morató X, Luján R, López-Cano M, Gandía J, Stagljar I, Watanabe M, et al. The Parkinson's disease-associated GPR37 receptor interacts with striatal adenosine A2A receptor controlling its cell surface expression and function in vivo. Sci Rep. 2017;7(1):9452.

19. Ravid R, Ferrer I. Brain banks as key part of biochemical and molecular studies on cerebral cortex involvement in Parkinson's disease. FEBS J. 2012; 279(7):1167-76.

20. Ferrer I, Martinez A, Boluda S, Parchi P, Barrachina M. Brain banks: benefits, limitations and cautions concerning the use of post-mortem brain tissue for molecular studies. Cell Tissue Bank. 2008;9(3):181-94.

21. Braak H, Del Tredici K, Rüb U, de Vos RAl, Jansen Steur ENH, Braak E. Staging of brain pathology related to sporadic Parkinson's disease. Neurobiol Aging. 2003;24(2):197-211. 
22. Braak H, Braak E. Neuropathological stageing of Alzheimer-related changes Acta Neuropathol. 1991;82(4):239-59.

23. Fahn S, Elton R. Members of the UPDRS development committee. Unified Parkinson disease rating scale. In: Fahn S, Marsden CD, Calne DB, Goldstein M, editors. Recent developments in Parkinson's disease Vol II. Florham Park, NJ: Macmillan Health Care Information; 1987

24. Goetz CG, Poewe W, Rascol O, Sampaio C, Stebbins GT, Counsell C, et al. Movement Disorder Society task force report on the Hoehn and Yahr staging scale: status and recommendations. Mov Disord. 2004;19(9):1020-8.

25. Nasreddine ZS, Phillips NA, Bédirian V, Charbonneau S, Whitehead V, Collin I, et al. The Montreal Cognitive Assessment, MoCA: a brief screening tool for mild cognitive impairment. J Am Geriatr Soc. 2005;53(4):695-9.

26. Chaudhuri KR, Martinez-Martin P, Schapira AHV, Stocchi F, Sethi K, Odin P, et al. International multicenter pilot study of the first comprehensive selfcompleted nonmotor symptoms questionnaire for Parkinson's disease: the NMSQuest study. Mov Disord. 2006;21(7):916-23.

27. Zigmond AS, Snaith RP. The hospital anxiety and depression scale. Acta Psychiatr Scand. 1983;67(6):361-70.

28. Tomlinson CL, Stowe R, Patel S, Rick C, Gray R, Clarke CE. Systematic review of levodopa dose equivalency reporting in Parkinson's disease. Mov Disord. 2010;25(15):2649-53.

29. Björkhem I, Lövgren-Sandblom A, Leoni V, Meaney S, Brodin L, Salveson L, et al. Oxysterols and Parkinson's disease: evidence that levels of 24Shydroxycholesterol in cerebrospinal fluid correlates with the duration of the disease. Neurosci Lett. 2013;555:102-5.

30. McKhann GM, Knopman DS, Chertkow H, Hyman BT, Jack CR, Kawas CH, et al. The diagnosis of dementia due to Alzheimer's disease: recommendations from the National Institute on Aging-Alzheimer's association workgroups on diagnostic guidelines for Alzheimer's disease. Alzheimers Dement. 2011;7(3):263-9.

31. Clark JD, Gebhart GF, Gonder JC, Keeling ME, Kohn DF. Special report: the 1996 guide for the care and use of laboratory animals. ILAR J. 1997;38(1):418.

32. Durrenberger PF, Fernando S, Kashefi SN, Ferrer I, Hauw JJ, Seilhean D, et al. Effects of antemortem and postmortem variables on human brain mRNA quality: a BrainNet Europe study. J Neuropathol Exp Neurol. 2010;69(1):7081.

33. Barrachina M, Castaño E, Ferrer I. TagMan PCR assay in the control of RNA normalization in human post-mortem brain tissue. Neurochem Int. 2006; 49(3):276-84.

34. Longo PA, Kavran JM, Kim MS, Leahy DJ. Transient mammalian cell transfection with polyethylenimine (PEI). Methods Enzymol. 2013;529:22740.

35. Murakami T, Shoji M, Imai Y, Inoue H, Kawarabayashi T, Matsubara E, et al. Pael-R is accumulated in Lewy bodies of Parkinson's disease. Ann Neurol. 2004;55(3):439-42.

36. Pándy-Szekeres G, Munk C, Tsonkov TM, Mordalski S, Harpsøe K, Hauser AS, et al. GPCRdb in 2018: adding GPCR structure models and ligands. Nucleic Acids Res. 2018:46(D1):D440-6.

37. Meyer RC, Giddens MM, Schaefer SA, Hall RA. GPR37 and GPR37L1 are receptors for the neuroprotective and glioprotective factors prosaptide and prosaposin. Proc Natl Acad Sci U S A. 2013;110(23):9529-34.

38. Liu B, Mosienko V, Vaccari Cardoso B, Prokudina D, Huentelman M, Teschemacher AG, et al. Glio- and neuro-protection by prosaposin is mediated by orphan G-protein coupled receptors GPR37L1 and GPR37. Glia. 2018;66(11):2414-26.

39. Hertz E, Terenius L, Vukojević V, Svenningsson P. GPR37 and GPR37L1 differently interact with dopamine 2 receptors in live cells. Neuropharmacology. 2019;152:51-7.

40. Berger BS, Acebron SP, Herbst J, Koch S, Niehrs C. Parkinson's diseaseassociated receptor GPR37 is an ER chaperone for LRP6. EMBO Rep. 2017; 18(5):712-25.

41. Flaumenhaft R, De Ceunynck K. Targeting PAR1: now what? Trends Pharmacol Sci. 2017;38(8):701-16.

42. Sako W, Murakami N, Izumi Y, Kaji R. Reduced alpha-synuclein in cerebrospinal fluid in synucleinopathies: evidence from a meta-analysis. Mov Disord. 2014;29(13):1599-605.

43. Parnetti L, Chiasserini D, Bellomo G, Giannandrea D, de Carlo C, Qureshi MM, et al. Cerebrospinal fluid tau/a-synuclein ratio in Parkinson's disease and degenerative dementias. Mov Disord. 2011;26(8):1428-35.
44. Eusebi P, Giannandrea D, Biscetti L, Abraha I, Chiasserini D, Orso M, et al. Diagnostic utility of cerebrospinal fluid a-synuclein in Parkinson's disease: a systematic review and meta-analysis. Mov Disord. 2017;32(10):1389-400.

45. Wang L, Gao L, Tang H, Nie K, Wang L, Zhao J, et al. Cerebrospinal fluid alpha-synuclein as a biomarker for Parkinson's disease diagnosis: a systematic review and meta-analysis. Int J Neurosci. 2015;125(9):645-54

46. Fairfoul G, MCGuire LI, Pal S, Ironside JW, Neumann J, Christie S, et al. Alphasynuclein RT-QulC in the CSF of patients with alpha-synucleinopathies. Ann Clin Transl Neurol. 2016;3(10):812-8.

47. Segovia F, Górriz JM, Ramírez J, Álvarez I, Jiménez-Hoyuela JM, Ortega SJ. Improved parkinsonism diagnosis using a partial least squares based approach. Med Phys. 2012;39(7):4395-403.

48. Saari L, Kivinen K, Gardberg M, Joutsa J, Noponen T, Kaasinen V. Dopamine transporter imaging does not predict the number of nigral neurons in Parkinson disease. Neurology. 2017:88(15):1461-7.

49. Hyman BT, Phelps CH, Beach TG, Bigio EH, Cairns NJ, Carrillo MC, et al. National Institute on Aging-Alzheimer's association guidelines for the neuropathologic assessment of Alzheimer's disease. Alzheimers Dement. 2012;8(1):1-13.

\section{Ready to submit your research? Choose BMC and benefit from:}

- fast, convenient online submission

- thorough peer review by experienced researchers in your field

- rapid publication on acceptance

- support for research data, including large and complex data types

- gold Open Access which fosters wider collaboration and increased citations

- maximum visibility for your research: over $100 \mathrm{M}$ website views per year

At BMC, research is always in progress.

Learn more biomedcentral.com/submissions 